\title{
4
}

\section{Easing Entry into the Scholarship of Teaching and Learning Through Focused Assessments: The "Decoding the Disciplines" Approach}

\author{
Joan Middendorf, David Pace \\ Indiana University
}

Students' difficulty in mastering material can motivate faculty toward the scholarship of teaching and learning (SoTL) if instructors' frustration can be framed as a researchable question, and they have practical models for assessing learning outcomes. The "decoding the disciplines" approach supports this shift from reflective teaching to SoTL. By focusing on narrowly defined bottlenecks to learning, faculty define researchable questions convincing to their disciplines. The specificity of these inquiries makes the assessment of learning much easier through the application of existing tools, such as those provided in Angelo and Cross's Classroom Assessment Techniques (1993). Example of specific assessments are provided.

\section{Getting Past the " $A$ " Word}

There is nothing quite like the word assessment to clear a room of faculty. It immediately evokes images of mindless evaluations imposed by an educational bureaucracy that has no real understanding of the forms of knowledge or the traditions that shape academic disciplines. And even instructors who are willing to entertain the possibility of finding ways to assess learning in their classes often find it difficult to form effective strategies to accomplish this goal.

This situation poses serious problems for the scholarship of teaching and learning (SoTL). If the work in this new field is to have a real impact on what 
actually happens in the classroom, its findings must have legitimacy in the eyes of those who are positioned to implement them. This requires some form of assessment that makes claims in the SoTL literature credible. But the creation of such assessments often seems to be beyond the abilities of the faculty who are conducting this research. Those faculty who are new to SoTL often assume that it requires the kind of evidence long identified with traditional social sciences. Faculty who have never had a day's training in quantitative methods set out on a fruitless quest for numbers to crunch, double-blind tests of pedagogical efficacy to administer, and variables to correlate. Not surprisingly, such efforts generally fail. Even those who are better prepared to use such methods usually come to realize that the preconditions for such research do not exist in most of the real-life situations in which SoTL is typically generated.

The irony is that in many cases these methodologies would not produce the desired effect even if they were successfully implemented. Although higher education has attempted to discover generalizable principles to improve student learning, Shulman (2002) found, through his research on medical schools, that teaching is content and context specific: "Domain specificity is likely to be the hallmark of inquiry, learning, and teaching in a discipline" (p. vii). Large numbers of faculty are not apt to be swayed by arguments couched in an unfamiliar language and based on forms of legitimization that are alien to those accepted in their own disciplines. Professors of literature, for example, are only slightly more likely to change their approaches to instruction in response to scholarship based on strict statistical procedures than their counterparts in a mathematics department are to be swayed by a literary analysis.

The difficult task of generating assessments that are convincing to a member of a particular discipline is made even harder by the fact that faculty often begin by seeking to evaluate large and ill-defined qualities such as critical thinking. Such broadly defined skills are generally an aggregation of simpler operations, each of which must be present and functioning correctly for the learning to take place. A global assessment of critical thinking cannot tell us which ones have not been sufficiently mastered.

Thus, if SoTL is to realize its potential, it will be necessary to find ways to focus the attention of its practitioners on clearly defined, manageable questions and to assess the results of classroom modules in a language that is meaningful to members of the relevant academic disciplines. We believe that the "decoding the disciplines" methods developed in the Indiana University Freshman Learning Project may be useful in overcoming these obstacles.

This chapter describes how we encouraged faculty who were deeply engaged in their disciplinary research to become involved in SoTL and to avoid the common mistakes of naïve teaching and learning research, such as 
we describe next. It provides examples of specific projects in a variety of disciplines.

\section{Naïve Attempts at Assessment}

There are currently 41 discipline-specific teaching journals in higher education (Weimer, 2006). The articles that comprise these journals often lack compelling evidence that learning has taken place. The standard format for these articles is to tell a "story," a detailed account of a new technique that a teacher has developed, often with no literature review and usually no assessment data beyond a claim that the students liked the new approach or that course evaluations improved. If they do present data, it commonly takes one of four forms. The first is a standard course evaluation showing improvement in the ratings following the implementation of a new approach (see the example in Table 4.1).

TABLE 4.1

Course Evaluation Improvement

Overall I would rate the quality of this course as outstanding.

Before new method $49 \%$

After new method

$83 \%$

In the second type, the course evaluation has been customized to allow students to rate themselves on a particular skill, the focus of the innovation (see the example in Table 4.2). Students rating themselves as improved at thesis writing are not providing very specific feedback to their instructor; thesis writing consists of many subskills.

TABLE 4.2

Student Skill Self-Rating

My skills at formulating a thesis:
A. greatly improved
B. improved
C. stayed the same
38
D. regressed 
The third approach to providing evidence that a learning innovation succeeded is to show improved exam scores the semester after a new technique is used (see the example in Table 4.3).

\section{TABLE 4.3}

Exam Score Increases Following Innovation

\begin{tabular}{|lc|}
\hline & Percent Increase \\
First exam & $6 \%$ \\
Second exam & $11 \%$ \\
\hline
\end{tabular}

Finally, naïve educational researchers often attempt method comparison studies, in which the instructor compares the outcomes for two courses delivered in two different ways, such as lecture versus discussion or lecture versus computerized practice exercises. The problem with this research design is that in hundreds of such studies, the main result has shown that the medium has no effect on the learning (Clark, 1983; Russell, 2001). Another challenge of good research design is described by W. J. McKeachie, who writes that there are so many extraneous variables affecting student learning (from instructional methods, to media attributes, to learning style, etc.) that "any study in a natural setting is lucky to account for $3 \%$ to $5 \%$ of the variance" (personal communication, October 13, 1997). We have found it useful to help faculty avoid inappropriate research methodologies by showing them how to create their own focused assessments of student learning outcomes.

\section{The FLP and Preparation for Assessment}

Since 1998 the Freshman Learning Project (FLP) has been taking faculty through a two-week summer workshop in which they seek to develop new ways to increase learning in their classes. The seven-step "decoding the disciplines" process that is at the heart of the program has been described at length in other publications (Pace \& Middendorf, 2004). This process (see Figure 4.1) has proven highly effective in helping faculty find new ways to increase learning, and it has played a crucial role in reenergizing many faculty at midcareer. But it has also served the unanticipated function of drawing faculty into SoTL and of providing them the tools with which they can assess the results of the implementation of new teaching strategies. Moreover, it has given 
the FLP participants (called "fellows") ownership over the assessment process, assured that the qualities that are evaluated are central to their goals, and produced evaluations of success that are couched in terms familiar to other faculty in that discipline.

FIGURE 4.1

Decoding the Disciplines:

Seven Steps to Overcome Obstacles to Learning

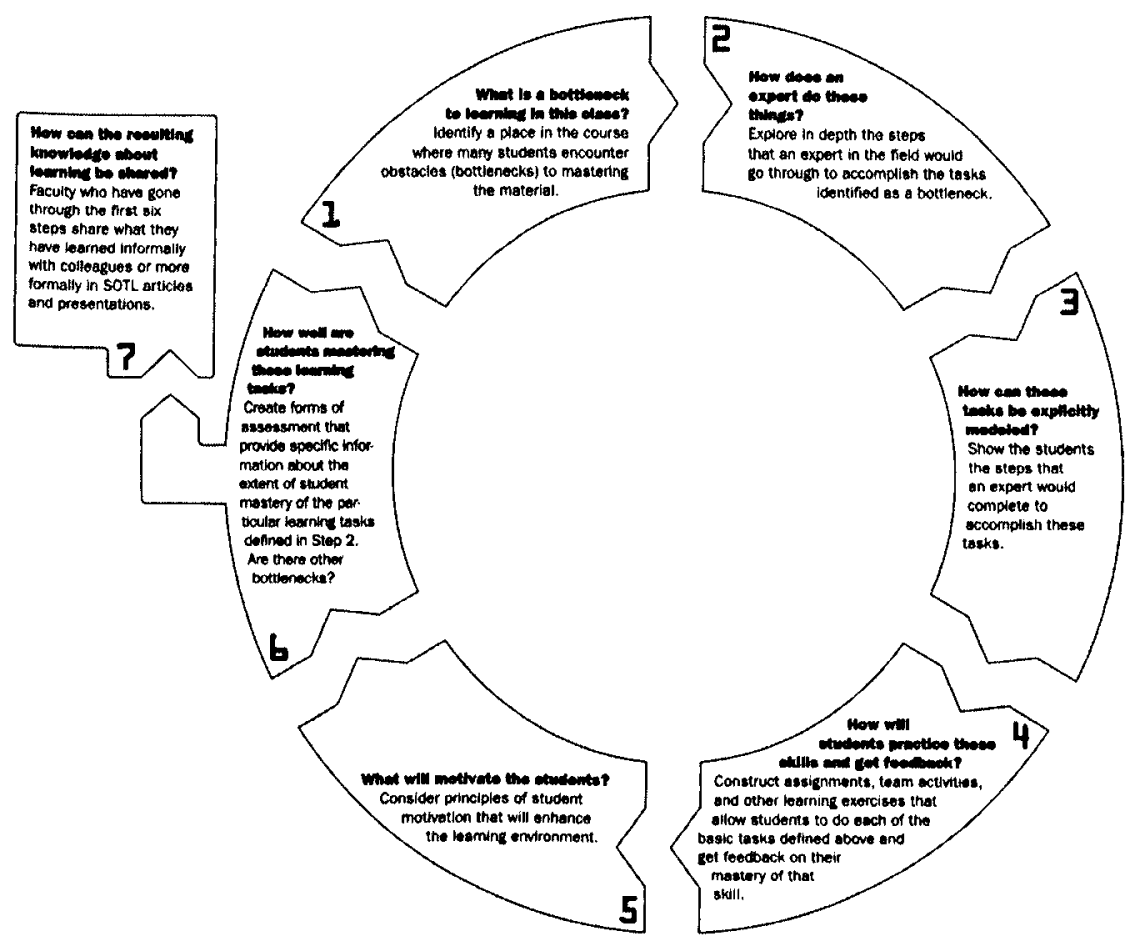

Source. Pace and Middendorf (2004, p. 3). Reprinted with permission.

At the beginning of this decoding the disciplines process each faculty fellow defines a bottleneck-that is, a place in one of his or her courses at which significant numbers of students fail to master material that is essential to the course. This might involve a complex theoretical issue such as the inability of students to understand the ways that light interacts with matter in an astronomy course or the characteristics of a painting that indicate that it was created in 16th-century Amsterdam. Or the bottleneck may involve a seemingly simple issue, such as how to distinguish between productive and unproductive details 
in the text of a literature course or how to generate objections to an argument in philosophy. Faculty find bottlenecks to be interesting problems to solve and they become as engaged in them as they are in their disciplinary research. Every discipline has numerous bottlenecks that deserve further exploration. (See Figure 4.2 for examples of bottlenecks grouped according to social sciences, sciences, and humanities.)

Once the bottlenecks have been clearly defined, fellows go through a lengthy interview in which they try to describe what steps an expert in the field would take to overcome the bottleneck. Their automatic responses are often somewhat superficial and jargon laden, but the interviewers probe to get beyond these to reveal the micro-operations that an expert does automatically and often unconsciously.

This process of defining bottlenecks and the procedures actually employed by experts in the field to overcome them may seem far removed from the assessment of learning, but, in fact, it can be a crucial step in reaching that end. This process focuses attention on specific, concrete forms of student behavior, whose presence or absence at various points in the course can be assessed, and it assures that the competencies being measured are in fact those that faculty members themselves have judged to be central to learning in their courses. By translating abstract critical thinking into concrete, discipline-specific sets of operations, a faculty member begins with a clear focus on defined skills that can be measured.

The details of the next several steps in the decoding the disciplines process (modeling the operations for students, giving them a chance to practice and receive feedback, and developing a strategy to motivate students to remain involved in the process), while somewhat peripheral to the issues of this chapter, often produce information that is highly useful in the assessment process, and they give faculty a motivation to conduct assessment because they are naturally curious about whether their interventions have proven effective.

\section{Getting Started in Assessment}

How do faculty who are untrained in pedagogical assessment move from the definition of learning operations to the evaluation of the success of particular interventions designed to teach these carefully defined ways of thinking? Before seeking to answer this question, it is worth noting that the form of the question may lead us to assume that there is a single process of evaluation that is appropriate to all teaching situations. As we noted earlier, such a one-sizefits-all approach ignores the differences in disciplinary practice and epistemology, and it can easily lead to assessments that are unacceptable or even 


\section{FIGURE 4.2}

\section{Bottleneck Examples from Varied Disciplines}

\section{Social Sciences}

- Economics: Students cannot correlate two dimensions of data on a graph.

- Logic: Students can translate simple logical propositions (e.g.,p and q) into colloquial language but get stuck translating nested, more intricate ones. For example, $(a=>(b$ or not c)).

- Sociology: For some students it is almost heretical to question the taken for granted cultural assumptions (success as wealth, inequalities, etc.) and structures (capitalism, democracy, globalization). This in turn blocks an understanding of what ideology even is.

\section{Sciences}

- Life science: Students seem unable to grasp why certain numbers are used for certain parts of the equation, what they represent, and how to look at their numbers and understand the values they are getting.

- Computer science: Students have difficulty distinguishing between conceptual design (real-world entities and the relationships among them) and logical design (representations of the real world which describe the levels among entities, the connections, data types, etc.).

- Biology: Students, who have been successful at memorization, do not know how to move beyond memorizing to start the problem-solving process.

- Genetics: Students are unable to move from terminology and verbal descriptions to visualizations of function or processes.

- Chemistry: Students do not grasp the formative mechanisms of acids and bases, and the similarities/differences between them. They are making incorrectly charged molecules.

- Chemistry: Students are intimidated by a problem with more than one math step. It is not the chemical principles that are confusing them but the mathematical manipulation required.

\section{Humanities}

- Art history: Students cannot apply the historical/contextual elements that influence artists and their work.

- Theater: Student actors find it difficult to maintain their courageous openness when they are in front of people and the pressure is on.

- Language: Students in a language class struggle to comprehend an unfamiliar word because they don't observe patterns of word endings and articles.

- English: The conflict or paradox of students asking for "freedom" when given a writing assignment and yet also wanting to know precisely what they "need" or "must" do to be successful.

Note. What may be perfectly simple in one discipline, may become a bottleneck if it is transferred to another. 
unintelligible to the very faculty it is designed to convince. As Shulman (2002) argues, "if different disciplines value particular forms of evidence and argument, narrative and explanation, then the pedagogies should reflect the same forms of representation and exposition" (p. vii).

Instead, the decoding the disciplines model encourages faculty to approach assessment within the context of the language and methods of their own fields. And the process of assessment does not need to be methodologically complex. In many cases the simple application of one of the strategies outlined in Angelo and Cross's Classroom Assessment Techniques (1993) can yield results that are quite adequate to convince members of a discipline of the effectiveness of a particular intervention.

In the FLP summer seminar we start simple:

- Fellows try one CAT per day to evaluate that day's session.

- We give them the Angelo and Cross book.

- We recommend three to five likely CATs to evaluate their lesson to narrow their choices.

- They select and use one CAT following their lesson.

- They complete CATs following the presentations of the 11 other FLP fellows.

- In small groups they recommend CATs relevant to other participants.

As part of the follow-up to the FLP seminar, fellows are expected to teach and assess their model lesson in a real class. They can either use the CAT they planned in the seminar, or they can meet with a team of assessment specialists, including an institutional review board consultant, to design the assessment that will be the basis for their SoTL project.

\section{Sample Assessments}

Here are some examples of the assessments that grew out of the decoding the disciplines process and were published by novices to SoTL (Pace \& Middendorf, 2004). Note the specificity and the variety.

\section{Assessing learning in a Literature Class}

As Gutjahr defined a bottleneck, "Students often cannot see the 'double and triple meanings' in a passage of text, and when I teach this, some students feel 
I am making the obvious obscure and even absurd" (Ardizzone, Breithaupt, \& Gutjahr, 2004, p. 50). To assess student ability to analyze text, he used CAT \#2, Focused Listing, before and after the lesson. Presented with an unfamiliar passage of text, students were asked to list as many meanings as they could. Results showed that following the lesson, $70 \%$ more of the students were able to go beyond plot summary to list at least two different possible interpretations of the text (see Figure 4.3). His analysis of the CAT revealed that the students had recognized more complex patterns and meanings in the text, and had to a greater degree than ever before unlocked the author's code of word choice and rhetorical strategy that are an important part of literary analysis.

FIGURE 4.3

Improvement in Meaning Interpretation

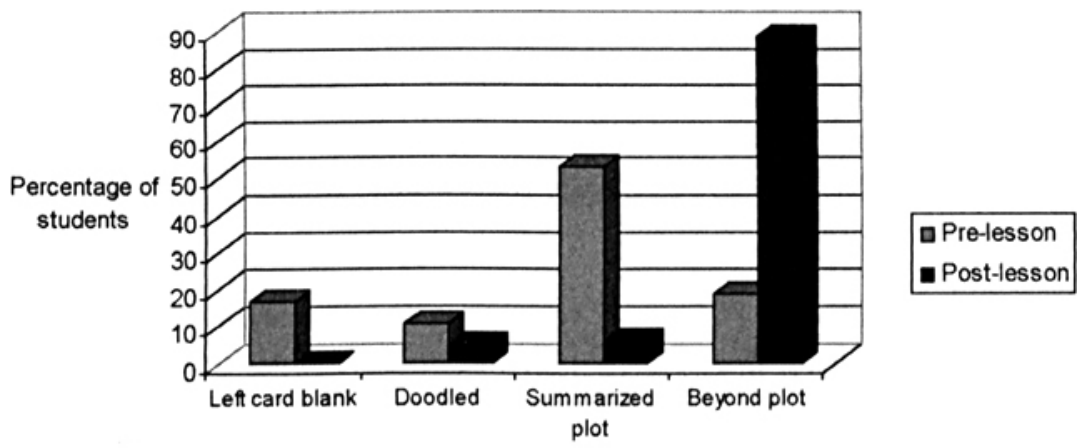

Response type

\section{Assessing learning in an Astronomy Class}

Pilachowski noticed astronomy textbooks include many schematic diagrams to illustrate astrophysical concepts. To a scientist these diagrams contain the kernels of astrophysical concepts, while the text serves primarily to flesh out the idea with further detail. In contrast, students' experience in other courses leads them to see illustrations and images as decoration or enrichment rather than as primary content. Students find it difficult to think visually in order to identify and master critical astronomy concepts (Durisen \& Pilachowski, 2004). With this bottleneck in mind, she applied CAT \#16, Concept Maps, asking students to sketch the Milky Way galaxy at the beginning of class and again at the end, including as much detail as they could. The frequency of particular features in the first and second drawings were counted and compared (see Figure 4.4). 
FIGURE 4.4

Analysis of Student Concept Maps of Milky Way Structures

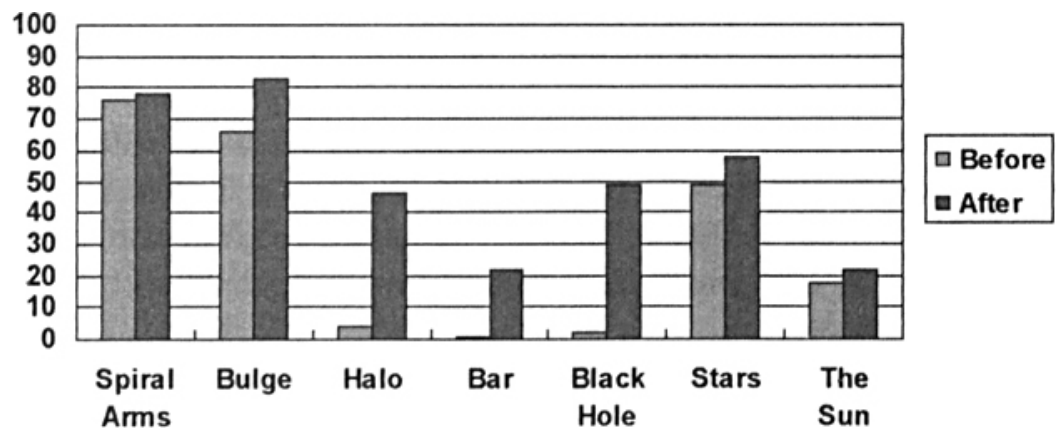

Not only did the students provide more detail at the end of the class than at the beginning, but she could identify the specific concepts where the increase was greatest or least, and thus gained insights into the specific details of visualizing astronomy.

\section{Materials for Practice Designing Assessments}

If you would like to have a faculty group practice turning the bottleneck and expert thinking into assessments, Appendix 4.1 provides examples from four disciplines that specify concrete forms of learning for you to work with. Small groups can use these materials as the basis for discussion about how we would know if students could do this kind of thinking and create some assessments for each example.

\section{Moving from Assessments to SOTL}

In the "Sample Assessments" section, the questions and data analysis may seem crisp, and the generation of such data may seem straightforward. But the iterative process of getting to such results is often messy and complex (see Figure 4.5), as faculty follow the decoding disciplines steps, repeatedly revisiting the bottleneck and expert thinking to disaggregate the operations. When implementing their lesson with an actual class, the FLP fellows use several CATs because it is not always clear which one will provide the most constructive 
feedback. They may end up with several sets of student responses, but these are often initially ambiguous and require focused analysis. Because the results of such assessment have not been reported widely in the literature, we don't have a good order of magnitude estimates to judge whether a teaching strategy may be deemed successful. But these are the kinds of problems that faculty are already quite good at solving, and this process is fortunately often facilitated by the material on "Turning the Data You Collect into Useful Information," which follows each CAT in the Angelo and Cross book.

FigURE 4.5

Iterative Decoding the Disciplines Process to Produce SoTL

1. Define the bottleneck and the steps by which an expert successfully addresses the bottleneck.

2. Repeat Step 1 several times to disaggregate the bottleneck and expert thinking operations.

3. Design a module to teach the bottleneck (following decoding disciplines Steps 3 through 6).

4. Implement and assess the module in an actual class.

5. Analyze the data.

6. Redefine the bottleneck and the steps by which an expert successfully addresses the bottleneck.

7. Write up the process using the decoding the disciplines steps as a framework.

In the literature assessment example, for instance, the literature professor, having read how the data from a Focused Listing can be used, compiled student answers into useful categories that showed the specific kinds of mistakes students made in finding the double and triple meaning in the text. Once he totaled the items in each category, he could write up his results in a way that would make sense to his colleagues. It was in analyzing and organizing the assessment results that he ascertained his orderly description for SoTL.

This process has narrowed the gap between classroom experience and published classroom research. Like many of their colleagues, the FLP fellows have "stories" to tell about strategies they have used to increase student learning. But unlike most of their colleagues, these instructors have a means to actually demonstrate the extent to which their experiments have been successful. Thus, it is not surprising that 16 of the fellows have published articles on their FLP projects, 18 have presented papers, and 4 have been awarded 
a total of almost $\$ 3.5$ million in grants to continue such work. This was the first foray into SoTL for most of these instructors, and several of them now make this work a regular part of their research agendas.

But beyond the usual academic outcomes, one of the most surprising aspects of decoding the disciplines has been its enthusiastic reception by faculty. By setting up a community of smart teachers, each one having identified a bottleneck, and providing them with the tools to explore their bottleneck, momentum is created, like a laboratory of rich questions. No longer is teaching a problem to be "fixed" (Bass, 1999). We have observed faculty literally run to their offices following a Step 2 interview, so eager are they to get their ideas on paper. Even several years after the summer seminar, faculty show up at meetings excited to discuss their ongoing efforts to explore bottlenecks. And the clarity of the method makes it easier to attract faculty into the process. When it was proposed to a large department to investigate the bottlenecks in their upper division courses, the proposal was accepted with unanimous acclamation-cheering and applause at a faculty meeting. The affective reactions to decoding the disciplines have impelled the project along as much as anything has.

\section{Conclusion}

If SoTL is to become an important part of higher education, it will be necessary to find effective mechanisms for drawing faculty into this new field of research. We believe that the combination of the decoding the disciplines process from the FLP with the CATs devised by Angelo and Cross provides such a mechanism. Bottlenecks serve as specific, visible points of entry to inquiry about student learning. The process of identifying them and of defining expert thinking focuses faculty from the outset on discrete operations that will allow them to later assess whether the bottleneck modules have actually had an impact on learning. The CATs can play a useful role in guiding instructors who are new to assessment through the process. The entire operation begins with problems that were defined by faculty themselves and, thus, is less likely to generate resistance to the process. The assessments do not require faculty to completely retool their methodologies, and the results are presented in a language that will not be foreign to other members of their discipline. 


\section{Appendix 4.1}

\section{Practice Turning Bottlenecks and Expert Operations into Assessments for Small Group Discussion}

Read the bottleneck and the expert thinking (Steps 1 and 2) for your disciplinary area. What evidence would indicate whether students could do this kind of thinking? Choose two or three applicable assessments from the Angelo and Cross CATs book, or invent your own.

\section{Philosophy (O'Connor, 2006)}

Step 1: Define the bottleneck:

Many students are unable to distill the basic structure of an author's argument.

Step 2: Define the steps an expert would follow to overcome this bottleneck:

a. Scan the entire passage to find the author's conclusion or thesis and the general line of argument.

b. Return to the text and identify the main points, dubious arguments, and unfamiliar terms.

c. Reconstruct the argument in a formal manner, making each step explicit, recognize the logical steps and the gaps in the argument.

d. Consider the best possible objections to premises that are most likely to be disputed.

\section{Creative Writing (Dorsey, 2006)}

Step 1: Define the bottleneck:

Students cannot distinguish between writing an autobiographical "chronology" of events ("plodding") from a carefully constructed fictional plot that gives the reader a sense of the causal relationship between the series of events and puts the dramatic situation into motion toward its inevitable conclusion through the actions of the character ("plotting").

Step 2: Define the steps an expert would follow to overcome this bottleneck:

1. Recognize that a chronological succession of events is not the same as a tightly integrated plot.

2. Generate realistic characters and a world within which the action can take place by asking:

a. Who is it happening to? Who are the characters involved?

b. Where is it happening?

c. Why to this character and why now?

d. How does this character behave, react? How is tension created?

e. What is at stake? What does a reader need to know about the character's situation to care about the outcome? 
f. When (the most important plot question) do they need to know each detail for maximum dramatic tension?

\section{Marketing (Rubin \& Krishnan, 2004)}

Step 1: Define the bottleneck:

Marketing decisions hinge on an accurate understanding of consumers and their decision processes. Although students generally understand how consumers make decisions, they are not able to reverse perspective and think like marketing managers. In particular, the bottleneck students face is that they do not know how to use information about consumer decision making to design actions that would influence those decisions.

Step 2: Define the steps an expert would follow to overcome this bottleneck of reversing perspectives:

a. Identify the set of attributes consumers use to make decisions about a product.

b. Describe the weights consumers assign to these attributes based on their underlying purchase motivations.

c. Translate how differences in motivation lead to the formation of decision rules.

d. Understand how to group consumers into different segments based on decision rules.

e. Identify the possible range of actions that could influence consumer decision rules.

f. Match specific actions with the types of decision rules used by consumer segments.

\section{Geology (Johnson \& Middendorf, 2007)}

Step 1: Define the bottleneck:

When faced with questions involving geological time, students do not understand that time is continuous. Students cannot move from the diagrams in the textbook to a meaningful understanding of geological time. They do not recognize that the events identified as a single point in time on the diagram (e.g., the origin or extinction of the dinosaurs) were actually spread over a great period of time. See the Geologic Time Scale at www.geosociety.org/science/timescale/timescl.htm.

Step 2: Define the steps an expert would follow to overcome this bottleneck:

a. Break down the geological column into its largest division, the eras, and explain the terminology.

b. Recognize that the bottom of the chart represents the oldest period, and the top the newest.

c. Identify where the present day is located on the time scale.

d. Identify and define the division boundaries and state their relation to origination and extinction events.

e. Remain aware that segments on the charts each represent long periods of time in which considerable change occurred. 


\section{References}

Angelo, T. A., \& Cross, K. P. (1993). Classroom assessment techniques: A handbook for college teachers (2nd ed.). San Francisco, CA: Jossey-Bass.

Ardizzone, A., Breithaupt, F., \& Gutjahr, P. (2004). Decoding the humanities. In D. Pace \& J. Middendorf (Eds.), New directions for teaching and learning: No. 98. Decoding the disciplines: Helping students learn disciplinary ways of thinking (pp. 50-55). San Francisco, CA: Jossey-Bass.

Bass, R. (1999, February). The scholarship of teaching: What's the problem? Inventio, l(1). Retrieved May 15, 2007, from the George Mason University, Division of Instructional Technology web site: www.doit.gmu.edu/Archives/feb98/randybass.htm

Clark, R. E. (1983, Winter). Reconsidering research on learning from media. Review of Educational Research, 53(4), 445-459.

Dorsey, R. (2006). Decoding creative plot development. Unpublished manuscript, Indiana University, Bloomington.

Durisen, R., \& Pilachowski, C. (2004.) Decoding astronomical concepts. In D. Pace \& J. Middendorf (Eds.), New directions for teaching and learning: No. 98. Decoding the disciplines: Helping students learn disciplinary ways of thinking (pp. 33-43). San Francisco, CA: Jossey-Bass.

Johnson, C., \& Middendorf, J. (2007). Decoding geologic time. Manuscript submitted for publication.

O'Connor, T. (2006). Decoding a philosophical argument. Unpublished manuscript, Indiana University, Bloomington.

Pace, D., \& Middendorf, J. (Eds.). (2004). New directions for teaching and learning: No. 98. Decoding the disciplines: Helping students learn disciplinary ways of thinking. San Francisco, CA: Jossey-Bass.

Rubin, B., \& Krishnan, S. (2004.) Decoding applied data in professional schools. In D. Pace \& J. Middendorf (Eds.), New directions for teaching and learning: No. 98. Decoding the disciplines: Helping students learn disciplinary ways of thinking (pp. 67-73). San Francisco, CA: Jossey-Bass.

Russell, T. (2001). The "no significant difference phenomenon" (5th ed.). Montgomery, AL: International Distance Education Certification Center.

Shulman, L. S. (2002). Foreword. In M. T. Huber \& S. P. Morreale (Eds.), Disciplinary styles in the scholarship of teaching and learning: Exploring common ground (pp. $\mathrm{v}$-ix). Sterling, VA: Stylus.

Weimer, M. (2006). Enhancing scholarly work on teaching and learning: Professional literature that makes a difference. San Francisco, CA: Jossey-Bass. 